\title{
Editorial: Transparency in Assessment-Exploring the Influence of Explicit Assessment Criteria
}

\author{
Anders Jönsson ${ }^{1 *}$ and Frans Prins ${ }^{2}$ \\ ${ }^{1}$ Kristianstad University, Kristianstad, Sweden, ${ }^{2}$ Department of Education, Faculty of Social and Behavioural Sciences, \\ Utrecht University, Utrecht, Netherlands
}

Keywords: self-regulation, transparency, assessment, criteria, rubrics

\section{Editorial on the Research Topic}

Transparency in Assessment-Exploring the Influence of Explicit Assessment Criteria

\section{OPEN ACCESS}

Edited and reviewed by:

Gavin T. L. Brown,

The University of Auckland,

New Zealand

*Correspondence:

Anders Jönsson

anders.jonsson@hkr.se

Specialty section:

This article was submitted to Assessment, Testing and Applied Measurement,

a section of the journal Frontiers in Education

Received: 11 December 2018 Accepted: 27 December 2018 Published: 15 January 2019

Citation:

Jönsson A and Prins F (2019)

Editorial: Transparency in

Assessment-Exploring the Influence

of Explicit Assessment Criteria.

Front. Educ. 3:119

doi: 10.3389/feduc.2018.00119
In many schools and higher education institutions it has become common practice to share assessment criteria with students. Sometimes it is required for accountability purposes, at other times criteria are used as a means to communicate expectations to students. Although it is generally and widely accepted that explicit assessment criteria should be shared with students, challenges to that assumption have been made. On the one hand, research has shown that explicit criteria may positively affect student performance, reduce their anxiety, as well as support students' use of self-regulated learning strategies. On the other hand, there are fears that explicit criteria may have a restraining influence on students' learning, as well as limiting their autonomy and creativity. Taken together, the question guiding this Research Topic is when, and under which conditions, transparency in assessment is productive for learning. The contributions to this Research Topic vary from conceptual approaches to more empirical oriented intervention studies.

\section{WHEN IS ASSESSMENT TRANSPARENCY BENEFICIAL?}

Brookhart, who performed a review of rubrics in higher education, might claim that whether transparency in assessment is productive for learning would depend on the criteria. If the criteria are true indicators of quality, then they have the potential to support student learning. On the other hand, most rubrics in her study proved to be beneficial for student learning, regardless of design. However, what is considered "beneficial" could be discussed. Even if studies on rubrics may report on improved performance, is it not always clear what kind of knowledge has been assessed. Was it, for instance, memory or conceptual knowledge? Convergent or divergent thinking? Short-term or long-term learning? Also, assessment transparency may yield an increase of student's self-efficacy and self-regulatory skills.

The connection between assessment transparency and student self-regulation is explored by several of the authors in this Research Topic. For example, Baartman and Prins, who performed a case study on meaning making of assessment criteria and standards, argue that detailed criteria may be detrimental for students' self-regulation, because it prevents them from choosing their own learning goals. According to them, transparency should therefore be viewed at the curriculum level, addressing what is expected of students at the end of the curriculum and in working life, and linked to the development of self-regulatory skills.

Balloo et al. on the other hand, argue in their conceptual study against the idea that transparency should necessarily foster "criteria compliance" (Torrance, 2007) and learner instrumentalism; instead they suggest that transparency is essential to promoting students' self-regulatory capacity. 
That leaves us with the intriguing question of how we can ascertain that transparency will foster one thing and not the other.

\section{PROVIDING TRANSPARENCY OF ASSESSMENT CRITERIA}

In this Research Topic, a few ways of providing transparency in assessment are described. Exemples are to explicitly describe criteria and expectations, to provide exemplars, or to have dialogues about assessment criteria with students.

According to Bearman and Ajjawi, transparency cannot be achieved merely through provision of explicit criteria (and maybe not at all), for instance since explicit criteria cannot capture tacit knowledge. This is to some extent corroborated by Balan and Jonsson, who did not find any clear effect of the level of explicitness of expectations on primary school students' motivation and performance in science. However, in the study by Holmstedt et al. pre-service teachers were able to analyze authentic situations with greater precision and at greater depth with the aid of explicit criteria. Apparently, divergent results are found, although it is not totally clear why the results differ.

One possible explanation for differential effects could be student ability, since low-performing and high-performing students responded quite differently to the intervention in the study by Balan and Jonsson. While the low-performing students increased their self-efficacy and performance quite dramatically, the impact on high-performing students was less pronounced. As suggested by previous research (Jonsson, 2014), high-performing students may even choose to ignore the criteria, since they want to manage on their own.

\section{CONNECTION TO PRACTICE}

Another important distinctions that emerges from the studies in this Research Topic is the grounding of criteria in the context of practice. In contrast to a "representational view of criteria" (Ajjawi and Bearman, 2018), where each criterion has one single meaning that does not change in relation to the context or the person who interprets them, a sociocultural view holds that explicit criteria are only "the tip of the iceberg." The greater part of the criteria is tacit, residing in practice (O'Donovan et al., 2004). Consequently, if detached from the practice to which they belong, criteria run the risk of being trivialized. In the study by Holmstedt et al., for example, students were not only provided with explicit criteria, but also guided in the practice of using them in context.

The connection to practice is also explored by Grainger et al. as well as by Bouwer et al. by using examples of authentic performance. Grainger et al. show that students accessed the exemplars regularly and found them useful in providing detailed guidance; a guidance that went beyond the descriptions of assessment tasks found in course outlines and assessment rubrics. Furthermore, students valued various types of exemplars, a range of quality, and the inclusion of annotated and unannotated versions of exemplars.
Bouwer et al. investigated whether students were better prepared for writing after working with a rubric or through learning by comparison. Although they found no effect of condition on the quality of the written essays, students in the comparative judgment condition provided relatively more feedback on higher order aspects, such as the content and structure of the text, as compared to students in the criteria condition.

\section{ASSESSMENT TRANSPARENCY IN HIGHER EDUCATION}

This brings us back to Brookhart, who showed that most uses of rubrics proved to be beneficial for student learning. However, similar to all empirical contributions in this Research Topic, with the exception of Balan and Jonsson, Brookhart's review only included studies from higher education. As already pointed out by Panadero and Jönsson (2013), there seems to be a difference between higher education and school settings. Whereas most interventions in higher education provide positive outcomes, even with no previous training, effects in schools are typically small, partial, or inconclusive-unless the intervention has a very long duration (i.e., several weeks). Not surprisingly, students in higher education are more skilled at using rubrics for self-regulation (i.e., planning, monitoring, and evaluating their performance). One explanation for this could be that students in higher education are older and more mature, or that they have more training in applying self-regulation strategies. Another explanation could be that higher education has a stronger connection to practice. This is evident for professional education, but may apply equally well for the arts and sciences. When studying geology at university, students not only learn the facts and theories of this subject, but also how to practice geology through both laboratory-, and field work. Criteria are therefore more likely to be considered in their context of practice.

\section{CONCLUSION}

We believe that the contributions of this Research Topic will bring the debate about assessment transparency a step further. The conceptual studies disclose considerations and mechanisms, whereas the empirical studies provide some evidence about how specific interventions have effects in practice. This may ultimately lead to process models concerning the effects of transparency of assessment criteria. For now, the studies point to some important prerequisites for transparency in assessment to be productive for student learning:

- First, criteria should be indicators of quality. Such criteria do not tell students what to do or how to do it, but how to discern important dimensions of quality in their own (or others') performance.

- Second, criteria need to be considered in their context of use, rather than being considered as generally applicable with a fixed meaning. Exemplars, modeling, and feedback can be used to "anchor" the criteria to a community of practice. 
- Third, students may need support to plan, monitor, and evaluate their performance with the aid of assessment criteria in order to foster learner autonomy and empowerment. Selfregulation does not necessarily occur spontaneously among students, but is a skill to be taught and learned.

\section{REFERENCES}

Ajjawi, R., and Bearman, M. (2018). "Problematising "standards": representation or performance?" in Developing Evaluative Judgement in Higher Education: Assessment for Knowing and Producing Quality Work, eds D. Boud, R. Ajjawi, P. Dawson, and J. Tai (Oxon; New York, NY: Routledge), 41-50.

Jonsson, A. (2014). Rubrics as a way of providing transparency in assessment. Assess. Eval. Higher Educ. 39, 840-852. doi: 10.1080/02602938.2013. 875117

O’Donovan, B., Price, M., and Rust, C. (2004). Know what I mean? Enhancing student understanding of assessment standards and criteria. Teach. Higher Educ. 9, 325-335. doi: 10.1080/1356251042000216642

Panadero, E., and Jönsson, A. (2013). The use of scoring rubrics for formative assessment purposes revisited: a review. Educ. Res. Rev. 9, 129-144. doi: 10.1016/j.edurev.2013.01.002

\section{AUTHOR CONTRIBUTIONS}

All authors listed have made a substantial, direct and intellectual contribution to the work, and approved it for publication.

Torrance, H. (2007). Assessment as learning? How the use of explicit learning objectives, assessment criteria and feedback in post-secondary education and training can come to dominate learning. Assess. Educ. Principl. Policy Pract. 14, 281-294. doi: 10.1080/09695940701591867

Conflict of Interest Statement: The authors declare that the research was conducted in the absence of any commercial or financial relationships that could be construed as a potential conflict of interest.

Copyright (c) 2019 Jönsson and Prins. This is an open-access article distributed under the terms of the Creative Commons Attribution License (CC BY). The use, distribution or reproduction in other forums is permitted, provided the original author(s) and the copyright owner(s) are credited and that the original publication in this journal is cited, in accordance with accepted academic practice. No use, distribution or reproduction is permitted which does not comply with these terms. 